\title{
Anesthesia Management of a Parturient with Generalized Psoriasis Who Underwent Planned Cesarean Section
}

\section{Elektif Sezeryanda Jenaralize Psöriazisli Bir Hastada Anestezi}

Gökçen BAŞARANOĞLU, Tark UMUTOĞLU, Mefkur BAKAN, Ufuk TOPUZ, Kadir IDIN, Ziya SALIHOĞLU

Department of Anaesthesiology and Reanimation, Bezmialem Vakif University, Faculty of Medicine, Istanbul, Turkey

\section{ABSTRACT}

Psoriasis is the most common chronic and inflammatory skin disease. The anesthetic approach may be regional or general. In this case, we described the anesthetic management of a parturient with generalized psoriasis who underwent a planned cesarean section.

Key Words: Psoriasis, anesthesia, pregnancy

\section{ÖZET}

Psoriasis derinin en sık görülen kronik inflamatuvar bir hastalığıdır. Anestezik yaklaşım genel ya da rejyonel olabilir. Bu olgu sunumunda elektif sezaryen planlanan jenaralize psoriasisi olan gebenin anestezi yönetimi sunulmuştur.

Anahtar Sözcükler: Psoriasis, anestezi, gebelik

\section{Giriş}

Psoriasis, kronik enflamatuvar bir hastalık olup klinik olarak çeşitli tiplere ayrılır. Anestezik seçim tutulan bölgeye, ek hastalıklara, beraberinde olabilecek enfeksiyona, enflamasyona ve hastalık için kullanılan ilaçlara göre değişebilir. Bu olgu sunumunda yaygın eritrodermik psoriasisli bir hastanın başarılı anestezi yönetimi sunulmuştur.

\section{Olgu}

Otuz-bir yaşında, $79 \mathrm{~kg}$ ağırlığında, $157 \mathrm{~cm}$ boyunda, 39 haftalık gebeliği olan, anamnezinde 3 abortusu olan olgu, elektif sezaryen ameliyatı için kadın hastalıkları ve doğum kliniğine başvurmuş. Vücudunun \%90'ına yakınını kaplayan diffüz eritem ve skuamı bulunan olgu, mevcut lezyonları için üre içeren losyon (Excipial lipo, Eczacıbaşı, İstanbul) kullanmaktaymış. Anamnezinde, eritrodermik psoriasis tanısı (6 yıl önce) konulmuş olan, metotreksat ve steroid tedavisi alan hastanın abortusları sonrasında araştırma amacıyla yapılan tetkiklerinde Faktör II Wild tip, Faktör V (Leiden) Wild tip, MTHFR A1298C heterozigot, MTHFR C677T heterozigot bulunmuş. Olgumuzun psoriasis için aldığı metotreksat ve steroid tedavisi gebelik planlaması nedeniyle gebelikten önce kesilmiş, yerine düşük molekül ağılıklı heparin (enoksaparin) başlanmış ve bu tedaviye gebelik boyunca devam edilmişti.

Rejyonel anestezi için kullanılabilecek enjeksiyon bölgesinin eritrodermik psoriasis ile tutulmuş olması nedeniyle genel anestezi altında sezaryen yapılmasına karar verildi (Resim 1). Laboratuvar tetkiklerinde bir özellik olmayan hastanın rutin monitorizasyonu, elektrokardiyografi (EKG), pulsoksimetre ve noninvaziv kan basıncı ölçümü ile yapıldı. Varis çorabı giydirilen hastada anestezi indüksiyonu lidokain $1 \mathrm{mg} / \mathrm{kg}$, propofol $2 \mathrm{mg} / \mathrm{kg}$ ve roküronyum $0,5 \mathrm{mg} / \mathrm{kg}$ ile sağlandıktan sonra orotrakeal entübe edildi. Canlı kız bebeğin abdominal doğumu sonrası, 1 ve 5 'inci dakikalarda APGAR skoru sırasıyla 8 ve 9 olan ve rutin uygulama olarak oksitosin verilen olgunun operasyonu sorunsuz geçti. Postoperatif analjezi amacıyla insizyon hattına subkütanöz olarak 10 cc \% 0,5 bupivakain infiltrasyonu uygulandı ve intravenöz yol ile $1 \mathrm{~g}$ parasetamol ve $100 \mathrm{mg}$ tramadol hidroklorür verildi. Derlenme ünitesinde $30 \mathrm{dk}$. komplikasyonsuz olarak izlenen hasta kadın hastalıkları ve doğum servisine teslim edildi. 


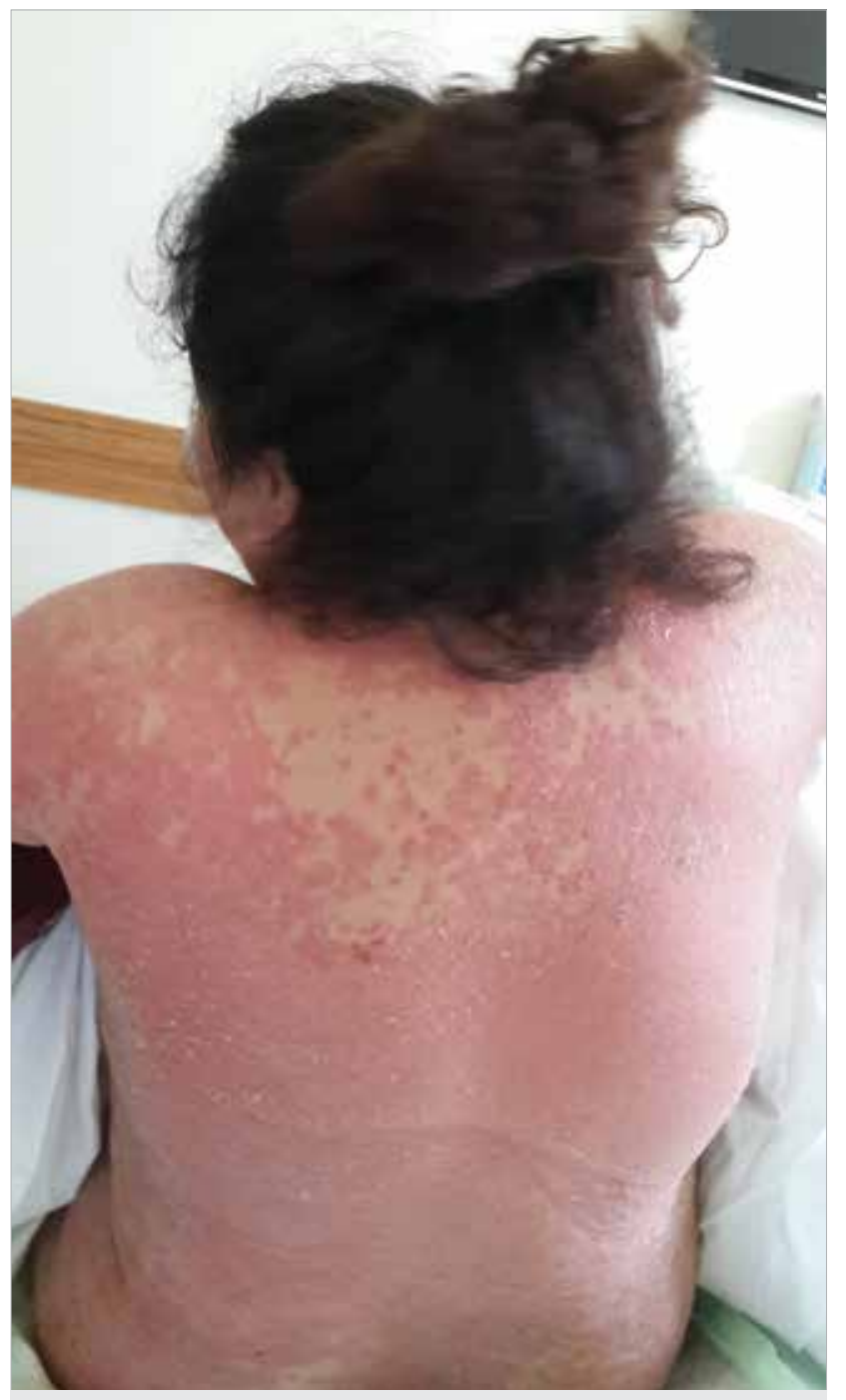

Resim 1. Eritrodermik psorizisli hastanın sırtı

\section{Tartı̧̧ma}

Psoriasisli hastalarda anestezik yönetim rejyonel anestezi veya genel anestezi ile olabilir. Anestezik yönetimin seçiminde psoriasisin klinik tipi, lezyonların yaygınlığı ve şiddeti önemlidir. Psoriasisin; plak psoriasis, guttat psoriasis, invers psoriasis, eritrodermik psoriasis ve püstüler psoriasis gibi klinik tipleri bulunmaktadır (1). Psoriasisde tutulum şiddeti psoriasis alan şiddet indeksi (PASI) ile hesaplanmaktadır. Buna göre 0-5 puan hafif, 5-10 puan orta, 10 ve üzeri puan şiddetli psoriasisi göstermektedir (2). Olgumuz, yüz, eller ve ayaklar dışında tüm vücudu tutan psoriasis lezyonları olma nedeni ile şiddetli kategorisinde kabul edilmiştir.

$\mathrm{Bu}$ tür hastaların perioperatif yönetiminde; steroid tedavisi alan hastanın steroid dozunun arttırılması önerilmektedir. Olgumuzda steroid tedavisi gebelik öncesi kesildiği için ilave doz steroid verilmemiştir. Dikkatli bir fizik muayene ve laboratuvar tetkikleri ile psoriasis ile ilgili enfeksiyon ya da enflamasyonun olup olmadığına bakılmalıdır. İmmünsupresan ilaç kullanan hastalarda karaciğer ve böbrek fonksiyonlarının değerlendirilmesi de önerilmektedir. İntraoperatif dönemde lezyonlu cilde travmadan kaçınılmalı ve tüm cilt travmadan korunmalıdır. Lezyonlu cilt bölgelerini koruyacak ya da kullanılması kontrendike olan herhangi bir ajan bildirilmemiştir. Nöroaksiyel blok kullanılması halinde opioidlerin kaşıntı yapıcı etkisinden dolayı kullanımları tekrar değerlendirilmelidir. Cilt travması sonrası yeni plak oluşumu ihtimalinden dolayı gerekli olmadıkça flasterler kullanılmamalıdır. İntravenöz kateterler dikilmeli ya da delikli sargılarla sarılmalıdır (3).

Eritrodermik psoriasis, kardiyovasküler, termoregülatuar ve metabolik sistemleri bozabilir. Bu olgularda tromboflebit, pulmoner emboli, serebrovasküler olay ve miyokard enfarktüsü görülebilir. Sepsis açısından dikkatli olunmalı, enfeksiyon bulguları varsa antibiyoterapi başlanmalıdır. Hastalar sıvı ve elektrolit dengesizlikleri açısından yakın takip edilmelidir. EKG elektrotlarını yerleştirmek güç olabilir. Tekrar eden polikontritisin eşlik ettiği püstüler psoriasisli hastalarda trakeal entübasyon, ödem dolayısıyla glottisin küçülmesi ve kartilaj dejenerasyonu sebebi ile güç olabilir. Hastamızda olası bir emboliye karşı varis çorabı giydirilip erken dönemde enoksaparin sodyum başlanmıştır. Rejyonel anestezi uygulamalarında Köbner fenomeni dikkate alınmalıdır. İlk kez 1876 yılında tarif edilen fenomen cilt travmasını takiben normal deride hastalıklı deri ile aynı olan lezyonun oluşmasıdır. Vitiligo, liken planus, liken niditus gibi diğer deri hastalıklarında da görülebilen bu fenomen en iyi psoriasisli hastalarda tarif edilmiştir. Genellikle travmayı takiben 8-10 (3 ya da 18 gün) gün sonra görülen bu fenomen, cilt travması ya da yapışkan bantlar, basınç uygulama, tıraş ya da insizyon yapma gibi herhangi bir irritasyon sonucu olabilir. Epidural veya spinal opioid alan hastalarda kaşıntı ile beraber tarif edilen bu fenomen medikolegal problemlere hazırlıklı olunması açısından irdelenmelidir (4-5). Psoriatik plakları olan hastalarda nöroaksiyel blok aktif enfeksiyon yokluğunda alternatif olabilir (6).

\section{Sonuç}

Psoriasisli hastalarla karşılaşıldığında hastalığın tipi, yaygınlığ1, ciddiyeti, kullanmakta olduğu ilaçlara dikkat edilmelidir. $\mathrm{Bu}$ nedenle bu hastalar ameliyat öncesi sıkı bir değerlendirmeye tabi tutulmalıdır. Eritrodermik psoriasis yüksek outputlu konjestif kalp yetmezliği gibi komplikasyonları nedeni ile ölümcül olabilir. Anestezist ve dermatoloğun aktif işbirliği ile peroperatif veya postoperatif komplikasyonlar azaltılabilir.

Informed Consent: Written informed consent was obtained from patient who participated in this case.

Peer-review: Externally peer-reviewed.

Author Contributions: Concept - G.B.; Design - T.U.; Supervision - Z.S.; Funding - K.I.; Materials - M.B.; Data Collection and/or Processing - U.T.; Analysis and/or Interpretation - G.B.; Literature Review - G.B.; Writing M.B.; Critical Review - T.U.

Conflict of Interest: No conflict of interest was declared by the authors.

Financial Disclosure: The authors declared that this case has received no financial support. 
Hasta Onamı: Yazılı hasta onamı bu olguya katılan hastalardan alınmışır.

Hakem Değerlendirmesi: Dış bağımsız.

Yazar Katkıları: Fikir - G.B.; Tasarım - T.U.; Denetleme - Z.S.; Kaynaklar K.I.; Malzemeler - M.B.; Veri Toplanması ve/veya İşlemesi - U.T.; Analiz ve/ veya Yorum - G.B.; Literatür Taraması - G.B.; Yazıyı Yazan - M.B.; Eleştirel İnceleme - T.U.

Çıkar Çatışması: Yazarlar çıkar çatışması bildirmemişlerdir

Finansal Destek: Yazarlar bu olgu için finansal destek almadıklarını beyan etmişlerdir.

\section{Kaynaklar}

1. Berth-Jones J. Psoriasis. Medicine 2005; 33: 50-5. [CrossRef]

2. Onsun N. Psoriasis tedavi yöntemleri ve algoritmik yaklaşım. Turkderm 2008; 42: 31-41.

3. Baluch A, Kak A, Saleh O, Lonadier L, Kaye AD. Psoriasis and anesthetic considerations. Middle East J Anesthesiol 2010; 20: 621-9.

4. Mahajan R. Neuraxial opioids and psoriasis. Int J Obstet Anesth 2008; 17: 375. [CrossRef]

5. Mahajan R, Kumar Grover V. Neuraxial opioids and Koebner phenomenon: implications for anesthesiologists. Anesthesiology 2003; 99: 229-30. [CrossRef]

6. Jackson M, Bird J, Fearfield L. Neuroaxial blockade and psoriasis. Int J Obstet Anesth 2008; 17: 80-1. [CrossRef] 